\title{
Formation and Novel Functions of Self-assembled Monolayers of Thiol Derivatives
}

\begin{abstract}
Kohei UOSAKI
Division of Chemistry, Graduate School of Science, Hokkaido University (Sapporo 060-0810, Japan)

Received August 9, 1999 ; Accepted September 6, 1999

A self-assembly (SA) technique has been very widely used to construct ordered molecular layers of various functionalities on a solid substrate and self-assembled monolayers (SAMs) of alkylthiols on gold have been the most well studied system. In this article, the SA process and typical functionalities of the SAMs of thiol derivatives are described mainly based on the results obtained in our group over the last 10 years. The structure and mass transport during the self-assembly process of the thiol derivatives on Au(111) were investigated by quartz crystal microbalance (QCM) measurement, polarization modulation Fourier transform infrared spectroscopy (PM-FTIR) and scanning tunneling microscopy (STM). The electrochemical characteristics and related mass transport and structural changes of the SAMs were carefully examined. The SAMs with novel functions such as uni-directional electron transfer, electrochemically generated chemiluminescence (ECL), visible light induced uphill electron transfer, and electrochemically controllable SHG activity were constructed. Finally, future prospects are presented.
\end{abstract}

\section{Key Words : Self-assembled Monolayer, Alkylthiol, Second Harmonic Generation, Photoinduced Electron Transfer}

\section{Introduction}

Self-assembled monolayers (SAMs) of thiol/disulfide derivatives, in general, and alkylthiols, in particular, on gold have attracted many research groups since Nuzzo and Allara showed that dialkyldisulfides (RS-SR) form oriented monolayers on gold surfaces in $1983^{1)}$ because they have many potential applications such as sensors, corrosion inhibition, wetting control, and biomolecular and molecular electronic devices. ${ }^{2-4)}$ Later, it was found that stable monolayers can be formed very easily not only on gold, but also on silver, copper, and platinum surfaces by soaking a metal substrate in a solution containing thiols or disulfides. ${ }^{2-4)}$ Most of the studies have been mainly made on gold, however, because gold does not have a stable oxide and, thus, it can be handled under ambient conditions.

Self-assembling molecules have three parts as depicted in Fig. 1. The first part is the surface active group that reacts with atoms on the substrate surface. Very strong molecule-substrate interactions result in

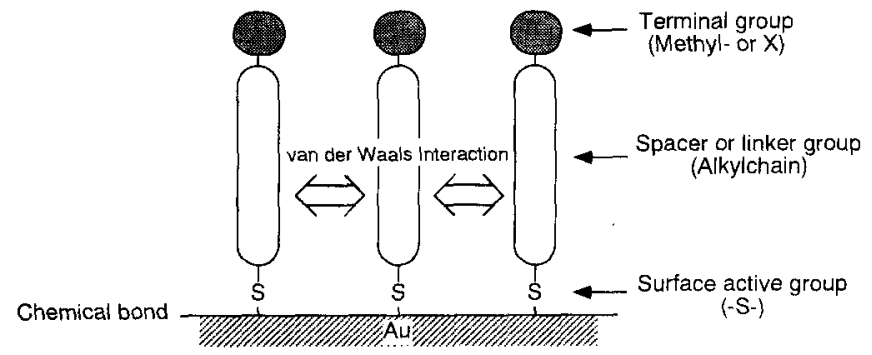

Fig. 1 A schematic drawing of a self-assembled monolayer. an apparent pinning of the surface active group to a specific site on the surface through a chemical bond. This is a covalent but slightly polar Au-S bond in the case of thiols on gold. The energies associated with the chemisorption are around $10 \mathrm{~kJ} / \mathrm{mol}^{2}{ }^{2}$ As a result of the exothermic surface active group-substrate interactions, the molecules occupy the available binding sites on the surface. The second molecular part is the alkyl chain. The highly ordered molecular layer is formed as a result of the short-range, dispersive, van der Waals forces among the alkyl chains. The energies associated with the attractive interchain van der Waals interactions are on the order of a few $\mathrm{kJ} /$ mol. ${ }^{2)}$ Thus, the self-assembly (SA) is achieved by a chemical bond formation between the substrate atoms and sulfur atoms of the thiols and the hydrophobic interaction between the alkyl chains. The third molecular part is the terminal group. In the case of a simple alkanethiol, it is a methyl group. By changing the terminal group from methyl to other functional groups, surfaces with various properties can be prepared.

In this work, the structure and mass transport during the self-assembly and electrochemical processes of the thiol derivatives on $\mathrm{Au}(111)$ were investigated by various techniques including the quartz crystal microbalance (QCM), Fourier transform infrared spectroscopy (FTIR) and scanning tunneling microscopy (STM), and SAMs of several novel functions were constructed. Although a wide variety of functionalities can be provided by self-assembled monolayers on solid surfaces, only those at the solid/ 


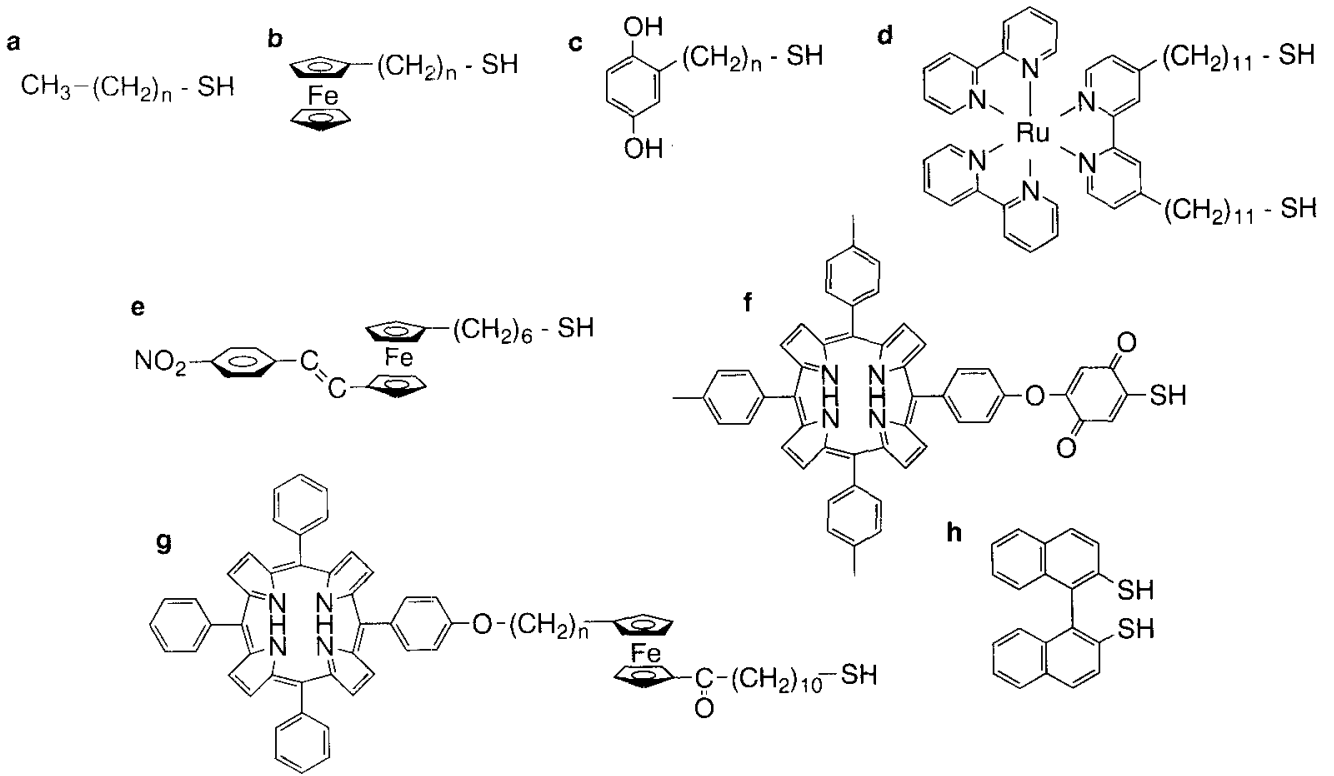

Fig. 2 Some of the molecules for the SAM formation used in this study.

electrolyte interfaces will be treated in the present article. Some of the molecules used in this study are shown in Fig. 2.

\section{Formation Process and Structure of SAMs on $\mathrm{Au}(111)$}

To construct well designed SAMs, it is essential to understand their detailed structure and growth process. Various techniques have been employed to determine the structure and to monitor the growth process of the SAMs. In this work, QCM, polarization modulation (PM-) FTIR and STM were used to follow the self-assembly process by monitoring the amount of adsorbates, molecular order and orientation of the SAMs, and the two-dimensional structure, respective$l y$, as a function of adsorption time.

\section{1 Adsorption kinetics of thiol on gold monitored by QCM}

QCM can detect the weight change at the submonolayer level and, therefore, is very useful to measure the amount of adsorbates as a function of time. ${ }^{5)}$ The SA process of ferrocenylundecanethiol (Fig. 2b: $\mathrm{FcC}_{11} \mathrm{SH}$ ) was examined in situ in a stirred hexane solution using a QCM on both sides of which gold was deposited. After the frequency became constant with time in pure hexane, the hexane solution of $\mathrm{FcC}_{11} \mathrm{SH}$ was added as indicated by a solid arrow in Fig. 3. The concentration of $\mathrm{FcC}_{11} \mathrm{SH}$ was $0.5 \mathrm{mM}$ after the addition. The frequency decreased, i.e., weight increased, significantly upon the addition, followed by a gradual frequency decrease. Since the addition of the same amount of pure hexane did not cause a frequency change except for a transient perturbation for a short period (Fig. 3, dotted arrow), the above mentioned shifts should be due to the adsorption of $\mathrm{FCC}_{11} \mathrm{SH}$ on the gold surface of the QCM. The adsorption was very fast during the initial stage and its rate was estimated from the slope to be $2 \times 10^{13}$ molecules $\mathrm{cm}^{-2} \mathrm{~s}^{-1}$. The subsequent adsorption was two orders of magnitude slower than the initial adsorption step and the rate of adsorption was $2 \times 10^{11}$ molecules $\mathrm{cm}^{-2} \mathrm{~s}^{-1}$. The frequency became constant around $800 \mathrm{~s}$ after the addition of $\mathrm{FcC}_{11} \mathrm{SH}$. The total frequency change during the adsorption of $\mathrm{FcC}_{11} \mathrm{SH}$ was $9.0 \mathrm{~Hz}$, which corresponds to $2.6 \times 10^{14}$ molecules $\mathrm{cm}^{-2}$. This number is in good agreement with the one expected for the monolayer coverage, i.e., $2.7 \times 10^{14}$ molecules $\mathrm{cm}^{-2}$, based on the calculation assuming a $0.66 \mathrm{~nm}$ diameter for the ferrocene group and a smooth $A u(111)$ surface.

2. 2 PM-FTIR investigation on the effect of adsorption time on the molecular order and orientation of the SAM

Although the QCM can follow the adsorption kinetics as described above, the adsorption time dependent order and orientation of the SAMs cannot be monitored by this technique. Thus, the selfassembly process was also monitored using PMFTIR $^{6)}$ that can give information about the monolayer structure on metal surfaces.

A PM-FTIR absorption spectrum of the $\mathrm{FcC}_{11} \mathrm{SH}$ SAM on a gold substrate showed three vibrational bands around 3100,2920 , and $2850 \mathrm{~cm}^{-1}$ in the $\mathrm{CH}$ stretching region. These peaks were assigned as the

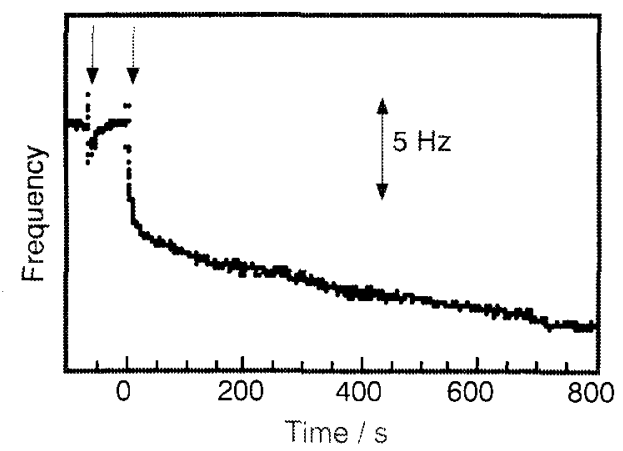

Fig. 3 Frequency response of the QCM in hexane when $\mathrm{FCC}_{11} \mathrm{SH}$ was added as indicated by a solid arrow. A dotted arrow shows the injection of pure hexane. 
$\mathrm{CH}$ stretching mode of the ferrocene ring $\left(\nu(\mathrm{CH})_{\mathrm{Fc}}\right)$, the asymmetric methylene stretching mode $\left(\nu_{\mathrm{as}}\left(\mathrm{CH}_{2}\right)\right)$, and the symmetric methylene stretching mode $\left(\nu_{\mathrm{s}}\left(\mathrm{CH}_{2}\right)\right)$, respectively. The positions of these bands are essentially the same as those previously reported. ${ }^{7)}$ The $\nu_{\mathrm{as}}\left(\mathrm{CH}_{2}\right)$ band of the $\mathrm{FcC}_{11} \mathrm{SH}$ monolayer on the gold substrate shifted to lower frequencies as the adsorption time increased $\left(2925 \mathrm{~cm}^{-1}\right.$ for $1 \mathrm{~min}, 2923$ $\mathrm{cm}^{-1}$ for $10 \mathrm{~min}$, and $2920 \mathrm{~cm}^{-1}$ for a $15 \mathrm{~h}$ adsorption). It should be mentioned, however, that even the $\nu_{\mathrm{as}}\left(\mathrm{CH}_{2}\right)$ of the $\mathrm{FCC}_{11} \mathrm{SH}$ monolayer for a 1 min adsorption was lower than that of the $\mathrm{FcC}_{11} \mathrm{SH}$ dissolved in fluorolube, i.e., in liquid state, $\left(2930 \mathrm{~cm}^{-1}\right)$. Similar tendencies were observed for the $\nu_{\mathrm{s}}\left(\mathrm{CH}_{2}\right)$ band. It is well known that the methylene stretching bands are observed at lower frequencies for samples in the crystalline state where the molecules are in the all trans conformation compared to those in the liquid state. ${ }^{8)}$ These results suggest that even monolayers formed within only 1 min have a certain degree of order and that the order increases with a longer self-assembly time. The $\mathrm{FcC}_{11} \mathrm{SH}$ monolayer prepared in $15 \mathrm{~h}$ approached the order of the solid state, as evidenced by $\nu_{\text {as }}\left(\mathrm{CH}_{2}\right)$ at $2920 \mathrm{~cm}^{-1}$. This value is very close to $2919 \mathrm{~cm}^{-1}$ of the octadecane (Fig. $2 \mathrm{a}: \mathrm{C}_{18} \mathrm{SH}$ ) monolayer, which is known to be very well ordered.

A longer adsorption time leads to narrower bands ( $32 \mathrm{~cm}^{-1}$ for $1 \mathrm{~min}, 30 \mathrm{~cm}^{-1}$ for $10 \mathrm{~min}$, and $20 \mathrm{~cm}^{-1}$ for the $15 \mathrm{~h}$ adsorption), i.e., a more uniform conformation distribution of $\mathrm{FcC}_{11} \mathrm{SH}$ molecules in the monolayer. A broader band reflects a greater nonhomogeneity in the distribution of the vibrational frequencies that is commonly due to a lack of order in the adsorbate overlayer.

The peak area of the $\nu_{\mathrm{as}}\left(\mathrm{CH}_{2}\right)$ band decreased with the self-assembly time. The peak area of a band such as $\nu_{\text {as }}\left(\mathrm{CH}_{2}\right)$ depends on both the amount and orientation of the adsorbed molecules. The QCM results described above showed that the number of $\mathrm{FcC}_{11} \mathrm{SH}$ molecules adsorbed on the gold substrate reaches almost $100 \%$ saturation in $30 \mathrm{~min}$. Therefore, the decrease in the absorbance of $\nu_{\mathrm{as}}\left(\mathrm{CH}_{2}\right)$ is not due to a decrease in the number of adsorbed molecules, but rather a change in the molecular orientation and conformation. Since p-polarized light interacts only with the dipole moment perpendicular to the surface, only the perpendicular component of the $\mathrm{C}-\mathrm{H}$ bonds absorbs p-polarized light. Thus, the decrease in the $\nu_{\text {as }}\left(\mathrm{CH}_{2}\right)$ band means that the tilt angle of the alkyl chain of the adsorbed $\mathrm{FcC}_{11} \mathrm{SH}$ molecules becomes smaller, i.e., the molecules stand closer to the surface normal, as the self-assembly time increases.

Based on these results, one can conclude that the order of the monolayer increases, the conformation distribution becomes more uniform and molecules stand more perpendicular to the surface, as the selfassembly time increases.

\section{3 In situ STM monitoring of evolution of two- dimensional order of the SAMs}

The self-assembly process was also followed in terms of the two-dimensional order by in situ STM. ${ }^{9,10)}$ Figure 4 shows STM images of Au(111) obtained at (a) $3 \mathrm{~min}$ and (b) $12 \mathrm{~min}$ after the addition of the modifying solution of $\mathrm{C}_{10} \mathrm{SH}$. Stripe structures as well as triangular pits were observed on the gold terrace just after the addition of the modifying solution (Fig. 4(a)). This stripe structure is similar to the one already reported under ultra-high vacuum (UHV) condition. ${ }^{11)}$ The depth of these pits is close to that of the gold monoatomic steps, i.e., $0.23 \mathrm{~nm}$ and, therefore, these pits should be the etch pits which were previously reported.,13) As time passed (Fig. 4(b)), islands, which are higher than the gold surface by $c a$. $0.2 \mathrm{~nm}$, were observed and grew two dimensionally with time. The size of the triangular pits increased only slightly, suggesting that the etching occurred at a very early stage of the SA process and was prevented by the adsorption of the molecules. A close-up image on the islands showed the molecular arrangement (Fig. 4(c)) corresponding to the $\sqrt{3} \times \sqrt{3}$ structure (Fig. 4(d)), which is the most well known structure of the SAMs of alkanethiols at saturated coverage. ${ }^{13)}$ The gold surface was almost fully covered with these islands 56 min after the addition of the modifying solution in this particular case.

The results of the QCM, PM-FTIR and STM showed that the SA process consists of the initial fast step, which corresponds to the physisorption in gas/ liquid states on and desorption from the gold surface of alkanethiols accompanied with the etching of the gold surface and the formation of the stripe phase, and the following slow step, which corresponds to the growth of the highly ordered $\sqrt{3} \times \sqrt{3}$ structure. This
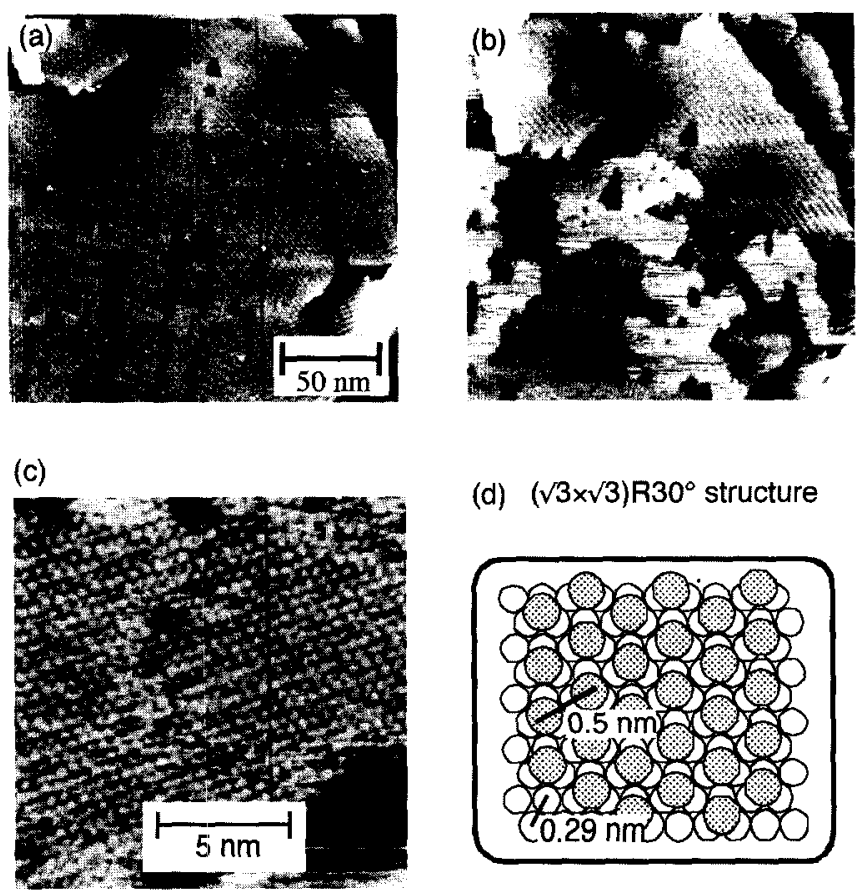

(d) $(\sqrt{3} \times \sqrt{3}) \mathrm{R} 30^{\circ}$ structure

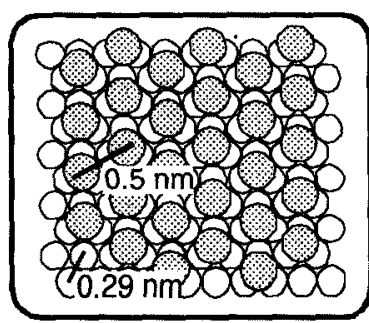

Fig. 4 STM images of an Au(111) surface obtained in situ at (a) $3 \mathrm{~min}$ and (b) $12 \mathrm{~min}$ after the addition of the modifying solution of $\mathrm{C}_{10} \mathrm{SH}$. (c) A close-up image on the islands observed in (b). (d) The molecular arrangement corresponding to the $\sqrt{3} \times \sqrt{3}$ structure. 
model is similar to the one proposed by Poirier and Pylant for the SA process in UHV. ${ }^{11}$

\section{Electrochemical Behaviors of SAMs}

Since many important functions of the SAMs involve the charge transport or redox process, the electrochemical characteristics of the SAMs have been quite extensively studied. Furthermore, the stability and amount of molecules in the SAMs can be electrochemically evaluated.

Widrig et al. reported that alkylthiolates are desorbed from a gold surface by the following one-electron reduction process in an alkaline ethanol solution. ${ }^{14)}$

\section{$\mathrm{Au}-\mathrm{SR}+\mathrm{e}^{-} \rightarrow \mathrm{Au}+\mathrm{RS}^{-}$}

One can determine not only the amount of the adsorbed thiolates from the integrated cathodic charge corresponding to the above reaction but also the adsorption energy from the position of the cathodic peak even when the thiolate has no electrochemically active groups. The thiol SAMs on gold also anodically decomposed and we proposed that the following reactions are involved in the anodic decomposition process based on the in situ FTIR study. ${ }^{15}$ )

$$
\begin{aligned}
& \mathrm{R}-\left(\mathrm{CH}_{2}\right)_{2} \mathrm{~S} \cdot \mathrm{Au}+3 \mathrm{H}_{2} \mathrm{O} \rightarrow \\
& \mathrm{R}-\left(\mathrm{CH}_{2}\right)_{2}-\mathrm{SO}_{2} \mathrm{OH}+5 \mathrm{H}^{+}+\mathrm{Au}+5 \mathrm{e}^{-} \\
& \mathrm{R}-\left(\mathrm{CH}_{2}\right)_{2}-\mathrm{SO}_{2} \mathrm{OH}+3 \mathrm{H}_{2} \mathrm{O} \rightarrow \\
& \mathrm{R}-\left(\mathrm{CH}_{2}\right)-\mathrm{COOH}+\mathrm{HSO}_{4}^{-}+7 \mathrm{H}^{+}+6 \mathrm{e}^{-} \\
& \text {R- }\left(\mathrm{CH}_{2}\right)-\mathrm{COOH}+\mathrm{Au} \rightarrow \\
& \mathrm{R} \cdot\left(\mathrm{CH}_{2}\right)-\mathrm{COO}^{-} \cdot \mathrm{Au}+\mathrm{H}^{+} \\
& \text {R- }\left(\mathrm{CH}_{2}\right)-\mathrm{COOH}+2 \mathrm{H}_{2} \mathrm{O} \rightarrow \\
& \mathrm{R}-\mathrm{COOH}+\mathrm{CO}_{2}+6 \mathrm{H}^{+}+6 \mathrm{e}^{-}
\end{aligned}
$$

\section{1 Electrochemical characteristics of ferrocene} terminated SAMs

Figure 5 shows the cyclic voltammogram (CV) and simultaneously recorded frequency change during the potential cycling of a gold QCM electrode, which was modified in $5 \mathrm{mM}$ ferrocenylundecane thiol $\left(\mathrm{FcC}_{11} \mathrm{SH}\right)$ hexane solution for $30 \mathrm{~min}$, measured in $1 \mathrm{M}(\mathrm{M}=\mathrm{mol}$. $\left.\mathrm{dm}^{-3}\right) \mathrm{HClO}_{4}$ (sweep rate, $50 \mathrm{mV} / \mathrm{s}$ ). ${ }^{16}$ ) A symmetrical reversible redox wave was observed around +260 $\mathrm{mV}$. This peak position agrees with the redox potentials of various previously reported ferrocene derivatives in solution. ${ }^{17)}$ Linear relations were observed

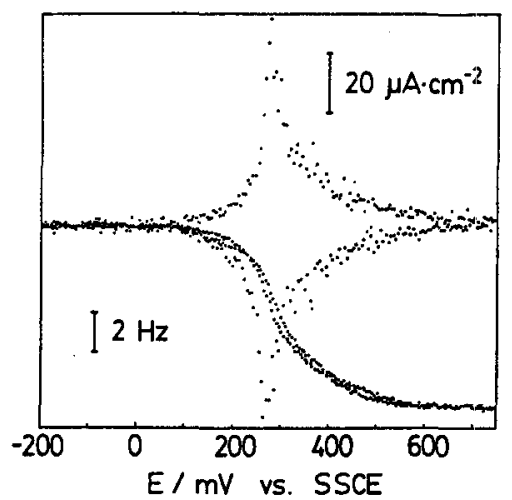

Fig. 5 A cyclic voltammogram and simultaneously recorded frequency change during the potential cycling of the gold QCM electrode, which was modified in $5 \mathrm{mM} \mathrm{FcC} \mathrm{m}_{11}$ $\mathrm{SH}$ hexane solution for $30 \mathrm{~min}$, measured in $1 \mathrm{M} \mathrm{HClO}_{4}$. Sweep rate: $50 \mathrm{mV} / \mathrm{s}$. between the sweep rate and the anodic and cathodic peak currents. These results showed that the redox peaks observed in the present study are due to the redox reaction of a ferrocene group immobilized on a gold electrode surface. The QCM response clearly showed that the frequency decreased upon the oxidation of the ferrocene moiety and returned to the initial value due to the reduction in the reverse potential scan. Since the frequency decrease means a mass gain at the QCM surface, it is concluded that the formation of the ferricenium cation is accompanied by anion uptake. Thus, the electrochemical process at the ferrocene SAM modified gold electrode can be expressed by:

$$
(\mathrm{Fc})_{\mathrm{M}}+\mathrm{X}^{-} \rightarrow\left(\mathrm{FC}^{+} \mathrm{X}^{-}\right)_{\mathrm{M}}+\mathrm{e}^{-}
$$

where $(\mathrm{Fc})_{\mathrm{M}}$ and $\left(\mathrm{Fc}^{+} \mathrm{X}^{-}\right)_{\mathrm{M}}$ are the ferrocene group, $\mathrm{Fc}$, and an ion-pair between the ferricenium cation and an anion, $\mathrm{Fc}^{+} \mathrm{X}^{-}$, immobilized on the surface, respectively. The mass gain was calculated as $100 \mathrm{~g}$ when $1 \mathrm{~mol}$ of electrons was passed in this particular case. This indicates that the $\mathrm{ClO}_{4}{ }^{-}$anion $(\mathrm{MW}=100)$ was not accompanied by solvent molecules during its movement to the SAM. We found, however, that this value significantly varied (100-600) depending on how the SAMs were formed and treated. ${ }^{5)}$ In general, smaller values were obtained at more densely packed monolayers. ${ }^{15,18)}$

If the ion-pair formation is involved in the electrochemical process at the ferrocene SAM modified gold, the positions of the redox peak should depend on both the nature and the concentration of the anion in solution as given by Eq. (1):

$$
\begin{aligned}
E= & E^{\circ}-(R T / F) \ln K+(R T / F) \ln \\
& \left(\left[\left(\mathrm{Fc}^{+} \mathrm{X}^{-}\right)_{\mathrm{M}}\right] /\left[(\mathrm{FC})_{\mathrm{M}}\right]-(R T / F) \ln \left[\mathrm{X}^{-}\right]\right.
\end{aligned}
$$

where $K$ is the formation constant of the ion pair, $\left(F C^{+} X^{-}\right)_{\mathrm{M}}$.

Figure 6 shows the anion concentration dependences of the peak potential at the $\mathrm{FcC}_{11} \mathrm{SH}$ SAM modified electrode in various electrolyte solutions. ${ }^{19}$ Linear relations were observed in all the cases. The slopes obtained in $\mathrm{HClO}_{4}$ and $\mathrm{HNO}_{3}$ solutions were 60 $\mathrm{mV} /$ decade as expected from Eq. (1) for monovalent anions, but were $30 \mathrm{mV}$ and $60 \mathrm{mV} /$ decade in dilute

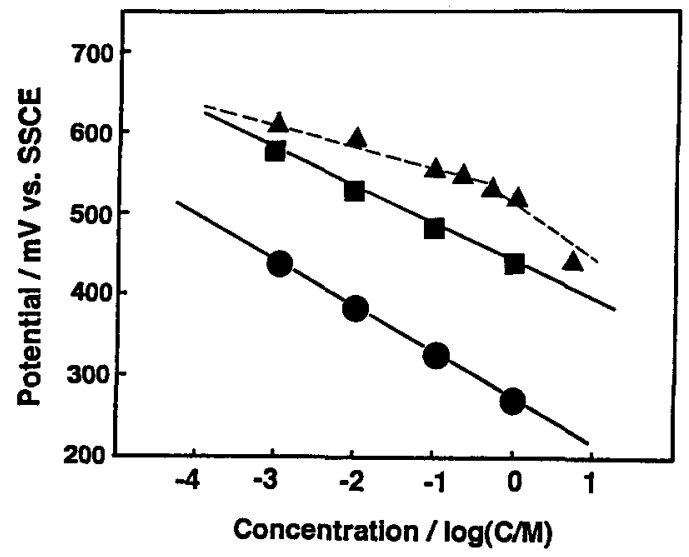

Fig. 6 Anion concentration dependences of the peak potential at the $\mathrm{FCC}_{11} \mathrm{SH}$ SAM modified electrode in various electrolyte solutions. 
up to $0.2 \mathrm{M}$ and in more concentrated $\mathrm{H}_{2} \mathrm{SO}_{4}$ solution, respectively. The slope of $30 \mathrm{mV} /$ decade suggests that ferricenium cation forms an ion-pair with a divalent anion, i.e., $\mathrm{SO}_{4}{ }^{2-}$. Since the $\mathrm{pKa}_{2}$ of $\mathrm{H}_{2} \mathrm{SO}_{4}$ is $1.92,{ }^{20)}$ the majority of anion species is $\mathrm{SO}_{4}{ }^{2-}$ when the $\mathrm{pH}$ is greater than 1.92 , i.e., the concentration of $\mathrm{H}_{2} \mathrm{SO}_{4}$ is less than $c a .5 \mathrm{mM}$. The present results, however, showed that the linear relation with a slope of $30 \mathrm{mV} /$ decade holds up to $0.2 \mathrm{M}$, suggesting that the ferricenium cation forms an ion-pair more easily with $\mathrm{SO}_{4}{ }^{2-}$ than with $\mathrm{HSO}_{4}{ }^{-}$. Equation (1) suggests that the larger the value of $K$, the more negative the redox potential. The anion dependent peak position at a given concentration shows that $K$ is in the order of $\mathrm{ClO}_{4}{ }^{-}>\mathrm{NO}_{3}{ }^{-}>\mathrm{SO}_{4}{ }^{2-}\left(\mathrm{HSO}_{4}{ }^{-}\right)$. Although the absolute value of the ion-pair formation constant cannot be determined, the relative ratio of the values for various anions can be determined from the values of the peak potential using Eq. (1). For example, the ratio between $K_{\mathrm{C} 104}{ }^{-}$and $K_{\mathrm{HSO} 4}{ }^{-}$can be calculated as $1.1 \times 10^{4}$. The ion-pair formation was also confirmed by other authors. ${ }^{21,22)}$

The formation of a charged layer seems to induce the structure change in the ferrocenylalkanethiol SAM as indicated by the subtractively normalized interfacial Fourier transform infrared reflectionabsorption (SNIFTIR) spectra ${ }^{23)}$ obtained at various potentials in $0.1 \mathrm{M} \mathrm{HClO}_{4}$ solution for the gold electrode, which was modified in $1 \mathrm{mM} \mathrm{FcC} \mathrm{F}_{11} \mathrm{SH}$ hexane solution for $2 \mathrm{hr}$, with the reference potential of +0.1 $\mathrm{V}$ where the terminal group existed as ferrocene. No band was found in the spectra when the potential was more negative than $+0.5 \mathrm{~V}$ where no oxidation of the ferrocene group took place. When the potential became more positive than $+0.5 \mathrm{~V}$, however, a downward band at $3113 \mathrm{~cm}^{-1}$ and two upward bands at 2923 and $2848 \mathrm{~cm}^{-1}$ were clearly observed in the $\mathrm{CH}$ stretching vibration region and the band intensity increased as the electrode potential became more positive and reached a limited value around $+0.8 \mathrm{~V}$ where the oxidation of the terminal ferrocene group was completed. As already mentioned, the downward peak at $3113 \mathrm{~cm}^{-1}$ and two upward peaks at 2923 and $2848 \mathrm{~cm}^{-1}$ were assigned as $\nu(\mathrm{CH})_{\mathrm{Fc}}, \nu_{\mathrm{as}}\left(\mathrm{CH}_{2}\right)$ and $\nu_{\mathrm{s}}\left(\mathrm{CH}_{2}\right)$, respectively. The upward and the downward bands in the SNIFTIR spectra mean weaker and stronger infrared absorption, respectively, at the sample potential than at the reference potential. Thus, the absorption of the $\nu(\mathrm{CH})_{\mathrm{FC}}$ band increased but those of the $\nu_{\text {as }}\left(\mathrm{CH}_{2}\right)$ and $\nu_{\mathrm{s}}\left(\mathrm{CH}_{2}\right)$ bands decreased upon oxidation of the ferrocene group. As p-polarized light was used for the measurement, the dipole for the $\mathrm{CH}$ vibration of ferrocene ring and methylene group became more and less, respectively, perpendicular to the surface, i.e., the alkyl chain became more perpendicular to the electrode surface, upon oxidation. Simultaneous measurements of SNIFTIRS and QCM were proved to provide much useful information about the ion-pair formation and structural change. ${ }^{15,24)}$
Dynamic ellipsometry measurements showed the thickness increase of the SAM by $0.3 \mathrm{~nm}$ upon oxidation of the ferrocene moiety of the $\mathrm{FcC}_{11} \mathrm{SH} \mathrm{SAM}$, thus confirming the ion-pair formation. ${ }^{25}$ )

The electrochemical characteristics of the SAMs of other ferrocene derivatives and on other substrates were also examined. The redox potential of the ferrocene moiety of the SAMs was found to be positively shifted upon introduction of an acyl group to the ferrocene ring. ${ }^{26)}$ The SAMs were less stable on the Pt substrate ${ }^{27)}$ and a smaller coverage was obtained on the ITO ${ }^{26,28)}$ although the electrochemical behaviors of the SAMs on these substrates were essentially the same as those on gold.

\section{2 Electrochemical characteristics of quinone} terminated SAMs

A proton coupled redox system was constructed using the hydroquinone/quinone terminated SAMs (Fig. 2c). Rather complicated $\mathrm{pH}$ dependent electrochemical characteristics were observed. ${ }^{29)}$ In contrast to the ferrocene terminated SAMs, the mass change was almost negligible and no orientation change was observed upon the redox of the quinone moiety in acidic solution. ${ }^{30}$ These results are reasonable as the terminal groups are neutral both in the oxidized and reduced states under the present experimental conditions.

\section{3 Uni-directional electron transfer at the fer- rocene terminated $\mathrm{SAMs}$}

The terminal groups of the SAMs can exchange electrons with species in solution and can act as an electron mediator if the redox potentials of the terminal group and solution species are properly chosen. For example, the surface ferrocene groups act as electron mediators for the reduction of $\mathrm{Fe}^{3+}{ }^{31,32)}$ Although reversible redox peaks are observed in $1 \mathrm{M}$ $\mathrm{HClO}_{4}+1 \mathrm{mM} \mathrm{Fe}\left(\mathrm{ClO}_{4}\right)_{3}$ solution at the bare gold electrode around $+450 \mathrm{mV}$, a cathodic current due to the reduction of $\mathrm{Fe}^{3+}$ was not observed at the $\mathrm{FcC}_{11} \mathrm{SH}$ SAM modified gold electrode in this potential region. The cathodic peak current around $+150 \mathrm{mV}$, however, grew if $\mathrm{Fe}\left(\mathrm{ClO}_{4}\right)_{3}$ was present in the solution and increased linearly with the $\mathrm{Fe}\left(\mathrm{ClO}_{4}\right)_{3}$ concentration. These results can be explained as follows. Since the redox potential of the $\mathrm{Fe}^{2+} / \mathrm{Fe}^{3+}$ couple in solution is more positive than that of the surface-attached ferrocene group, as soon as the ferricenium cation site is reduced to the neutral ferrocene at the potential more negative than the redox potential of the ferrocene group, the ferrocene group donates an electron to $\mathrm{Fe}^{3+}$. As a result, $\mathrm{Fe}^{2+}$ is formed and the ferrocene becomes the ferricenium cation that then accepts an electron from the electrode and the surface ferrocene is regenerated. These steps are repeated and a large cathodic current flows, as summarized in the following scheme.

$$
\begin{aligned}
\mathrm{Fc}^{+}+\mathrm{e}^{-} \rightarrow \mathrm{Fc} \\
\mathrm{Fc}+\mathrm{Fe}^{3+} \rightarrow \mathrm{Fc}^{+}+\mathrm{Fe}^{2+}
\end{aligned}
$$

The cathodic peak was the result of the limited 
diffusion of $\mathrm{Fe}^{3+}$ from the solution bulk to the surface. When the potential of the modified electrode was scanned back in the positive direction, the ferrocene moiety was oxidized to the ferricenium cation. The anodic current due to the electrochemical oxidation of the ferrocene groups was smaller than that without $\mathrm{Fe}^{3+}$ in solution, since a part of the ferrocene groups had already been oxidized to the ferricenium cation by $\mathrm{Fe}^{3+}$ in solution. Moreover, the compact surface monolayer inhibited the direct electron transfer from $\mathrm{Fe}^{2+}$ to the electrode. Thus, the oxidation of $\mathrm{Fe}^{2+}$ in solution did not take place at the modified electrode. In short, the $\mathrm{FcC}_{11} \mathrm{SH}$ SAM modified electrode acts as a rectifier or a diode. This is a very important property for constructing molecular electronic devices.

\section{Construction of SAMs of Special Functions}

By choosing the terminal group of the alkylthiols, one can construct interfaces with novel functions. Here, several examples are given.

\section{1 Electrochemically generated chemilumines- cence (ECL)}

$\mathrm{Ru}(\mathrm{bpy})_{3}{ }^{2+}$ is known to emit red light when it is electrochemically oxidized in solutions containing some species such as oxalate ion. The emission is called ECL. Here we attempted to form a SAM of $\mathrm{Ru}(\mathrm{bpy})_{3}{ }^{2+}$ - alkanethiol (Fig. 2d) on gold and ITO electrodes. ${ }^{33,34)}$

Although the SAM was successfully formed on a gold substrate, it was anodically decomposed in the potential region which was more negative than the redox potential of $\mathrm{Ru}(\mathrm{bpy})_{3}{ }^{2+13+}$ and, therefore, was not suitable to observe a stable ECL. On the other hand, the SAM on the ITO was stable and gave reasonably intense emission. The current-potential relations of the bare and the SAM modified ITO electrode in $0.4 \mathrm{M} \mathrm{Na}_{2} \mathrm{SO}_{4}$ solution containing $0.1 \mathrm{M}$ $\mathrm{Na}_{2} \mathrm{C}_{2} \mathrm{O}_{4}(\mathrm{pH}=4.7)$ showed that while an anodic current started to flow around $+1450 \mathrm{mV}$, which is much more positive than the standard redox potential of oxalic acid at the bare ITO electrode, the current started to increase at $+1050 \mathrm{mV}$ at the modified ITO electrode. Light was emitted from the modified electrode as soon as the anodic current started to flow and the light intensity sharply increased as the anodic current increased. The critical potential of +1050 $\mathrm{mV}$ agreed with the potential where the anodic current due to the oxidation of $\mathrm{Ru}(\mathrm{bpy})_{3}{ }^{2+}$ started to flow in a solution without $\mathrm{C}_{2} \mathrm{O}_{4}{ }^{2-}$. The spectrum of the emitted light had a peak at $650 \mathrm{~nm}$ which is close to that of the Ru-Complex in $\mathrm{CH}_{2} \mathrm{Cl}_{2}$ solution $(591 \mathrm{~nm}$ ), suggesting that the emission was from $\mathrm{Ru}(\mathrm{bpy})_{3}{ }^{2+*}$. These results indicate that the $\mathrm{Ru}(\mathrm{bpy})_{3}{ }^{2+/ 3+}$ groups of the SAM on the ITO electrode act as mediators for the oxidation of oxalate and the following processes take place in the anodic potential region. Thus, the emission is of ECL.

$$
\begin{aligned}
& \mathrm{Ru}(\mathrm{bpy})_{3}{ }^{2+} \rightarrow \mathrm{Ru}(\mathrm{bpy})_{3}{ }^{3+}+\mathrm{e}^{-} \\
& \mathrm{Ru}(\mathrm{bpy})_{3}{ }^{3+}+\mathrm{C}_{2} \mathrm{O}_{4}{ }^{2-} \rightarrow \mathrm{Ru}(\mathrm{bpy})_{3}{ }^{2+}+\mathrm{CO}_{2}+\mathrm{CO}_{2}{ }^{--} \\
& \mathrm{Ru}(\mathrm{bpy})_{3}{ }^{3+}+\mathrm{CO}_{2}{ }^{-} \rightarrow \mathrm{Ru}(\mathrm{bpy})_{3}{ }^{2+*}+\mathrm{CO}_{2} \\
& \mathrm{Ru}(\mathrm{bpy})_{3}{ }^{2+*} \rightarrow \mathrm{Ru}(\mathrm{bpy})_{3}{ }^{2+}+h \nu
\end{aligned}
$$

\section{2 Electrochemically controllable SHG activity}

Optical second harmonic generation ( $\mathrm{SHG}$ ) is a nonlinear process in which two photons of frequency $\omega$ are converted to a single photon of frequency $2 \omega$. The control of the second harmonic (SH) intensity by an external stimulus such as an electric or optical perturbation is very important in various applications. One of the promising systems in this respect is the electrochemical control of the SH property. Although it is known that the SH intensity depends on the electrode potential even at bare metal electrodes, ${ }^{35)}$ a more drastic effect is expected at electrodes modified with SAMs of molecules which have a high molecular polarizability (hyperpolarizability) and a redox moiety since high interfacial nonlinear polarizability is expected because of the highly ordered molecular arrangement, and both the molecular hyperpolarizability and molecular orientation are expected to be dependent on the oxidation state of the functional group of the SAM.

We have recently constructed novel SAM based systems at which the $\mathrm{SH}$ intensity can be electrochemically controlled for the first time. ${ }^{36}$ The systems consist of gold electrodes modified with the SAM of two novel molecules (trans-[1-(6-mercaptohexyl) ferrocenyl-2-(4-nitro-phenyl)ethylene] (Fig. 2 (e): $\left.\mathrm{NPEFcC}_{6} \mathrm{SH}\right)$ and trans-[1-(6-mercaptohexanoyl) ferrocenyl-2-(4-nitrophenyl)ethylene] (NPEFcCOC ${ }_{5}$. $\mathrm{SH}$, both of which have a ferrocenyl-nitrophenyl ethylene group as the SHG active groups. When the ferrocene moiety of the SAMs was electrochemically oxidized to the ferricenium cation, the SH intensity increased six times at the former electrode as shown in Fig. 7 and four times at the latter. The SH intensity decreased and returned to the original value when the

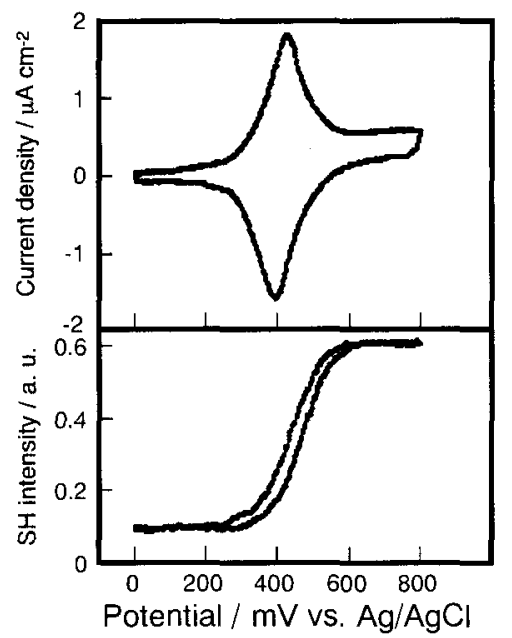

Fig. 7 Cyclic voltammograms and potential dependence of $1064 \mathrm{~nm}$-excited SHG $(532 \mathrm{~nm})$ at the $\mathrm{NPEFcC}_{6} \mathrm{SH}$ SAM modified gold electrodes measured in $0.1 \mathrm{M} \mathrm{HClO}_{4}$ solution with the scan rate of $5 \mathrm{mV} \mathrm{s}^{-1}$. The dipping time for the surface modification was $12 \mathrm{~h}$. 
ferricenium cation was reduced to the neutral ferrocene. These changes were reversible and repeated many times. The origin of the SH intensity change was found to be due to the changes in orientation of the SAM, which was measured using in situ FTIRRAS, and of the hyperpolarizabilities of these molecules, $\beta_{z z z}$, which were calculated by using a computational electronic structure model (ZINDO). ${ }^{36)}$

\section{3 Visible light induced uphill electron transfer}

Construction of a very efficient artificial photosynthesis system is one of the most important goals of modern chemistry. In natural photosynthesis systems, molecules of various functionalities are organized with molecular dimensions to achieve a very efficient system. Thus, one of the most interesting applications of SAM is the construction of an artificial photosynthetic system. We have now achieved a very efficient visible-light-induced photocurrent generation at gold electrodes modified with SAMs of novel molecules, which have porphyrin, quinone or ferrocene, and thiol groups as photoactive, electron transport/relay, and surface binding groups, respectively (Fig. 2f: $\mathrm{PQSH},{ }^{37,38)}$ Fig. $2 \mathrm{~g}: \mathrm{PC}_{\mathrm{n}} \mathrm{FCC}_{11} \mathrm{SH}^{39)}$ ). The alkyl chain was introduced in the latter molecule to examine the effect of the order of the SAM on the inhibition of the reverse electron transfer and energy transfer from the excited porphyrin to the gold electrode. Cyclic voltammograms of the $\mathrm{PQSH}$ and $\mathrm{PC}_{8} \mathrm{FcC}_{11} \mathrm{SH}$ SAM modified gold electrodes in a phosphate buffered 0.1 $\mathrm{M} \mathrm{NaClO}_{4}$ solution $(\mathrm{pH}=4.5)$ showed that the redox potentials of the quinone and ferrocene groups were $+210 \mathrm{mV}$ and $+640 \mathrm{mV}$ (vs. $\mathrm{Ag} / \mathrm{AgCl}$ ), respectively. Adsorbed amounts of the former and the latter on the gold electrode calculated from the charge of the redox peaks were $3.7 \times 10^{13}$ and $1.2 \times 10^{14}$ molecule $\mathrm{cm}^{-2}$, respectively, which corresponded to 270 and $83 \AA^{2} /$ molecule, respectively. Considering the areas of the perpendicular and flat porphyrin group orientations to be $c a$. 50 and $250 \AA^{2}$ molecule ${ }^{-1}$, respectively, one can conclude that the porphyrin groups were in a flat and perpendicular orientation in the PQSH and
$\mathrm{PC}_{8} \mathrm{FcC}_{11} \mathrm{SH} \mathrm{SAM}$, respectively, and the latter monolayer was relatively well ordered.

The photoelectrochemical characteristics of these electrodes were investigated in a phosphate-buffered solution $(\mathrm{pH}=4.5)$ containing $5 \mathrm{mM}$ methylviologen $\left(\mathrm{MV}^{2+}\right)$ as the electron acceptor. A stable cathodic photocurrent flowed as soon as the electrode was illuminated and fell instantly when illumination was terminated if the potential was more negative than +200 and $+650 \mathrm{mV}$ for the former and the latter, respectively, which coincide with the redox potentials of the relay groups in the SAM. The photocurrentpotential relations of these electrodes are shown in Fig. 8. These results confirmed that the photoinduced electron transfer took place through the electron relay. The reduction of $\mathrm{MV}^{2+}$ to the methylviologen cation radical $\left(\mathrm{MV}^{+}\right)$was confirmed as the color of the solution in front of the $\mathrm{PC}_{8} \mathrm{FcC}_{11} \mathrm{SH} \mathrm{SAM}$ electrode changed to blue after prolonged illumination. Since the redox potential of $\mathrm{MV}^{2+} / \mathrm{MV}^{+}$is -630 $\mathrm{mV}$, we have achieved an uphill transport of electrons by visible light illumination at these interfaces. The shapes of the photocurrent action spectra of both systems were in very good agreement with the absorption spectra of the SAMs, confirming that the porphyrin group in the SAMs really acted as a photoactive site.

The quantum efficiencies based on the number of photons adsorbed by the SAM at $-200 \mathrm{mV}$ were 0.3 and $11 \%$ for the former and latter electrodes, respectively. The latter is the highest quantum efficiency ever reported for photoinduced electron transfer at a monolayer modified metal electrode. The inset of Fig. 8 shows the energy diagram for the photoinduced electron transfer at these electrodes in a solution containing an electron acceptor. At least two reasons can be considered to explain why the latter system showed such a very high efficiency. One is the high electron transfer rate from the gold electrode to the ferrocene that was electrochemically proved. The other is the effective inhibition of reverse electron

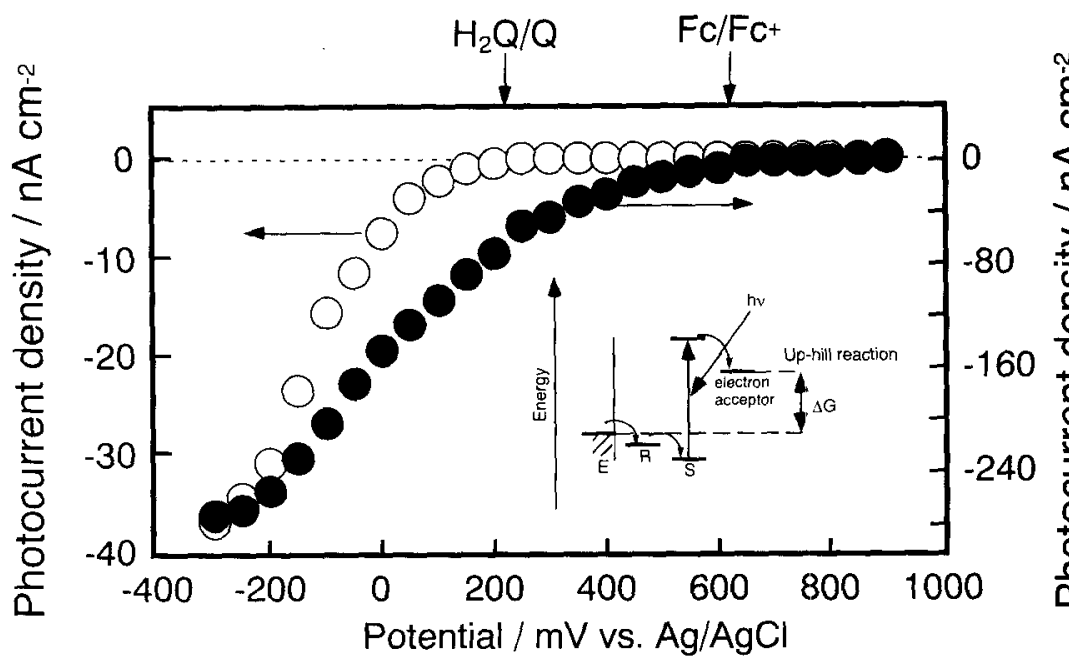

Fig. 8 Photocurrent-potential relations at the $\mathrm{PQSH}$ (O) and $\mathrm{PC}_{8} \mathrm{FcC}_{11} \mathrm{SH}$ (O) SAM modified gold electrodes in a phosphate buffered solution $(\mathrm{pH}=4.5)$ containing $5 \mathrm{mM} \mathrm{MV}^{2+}$. Inset : Energy diagram for these interfaces. 
transfer and/or energy transfer from the excited state of the porphyrin moiety to the gold electrode because of the highly ordered structure of the latter as already mentioned. Angle resolved x-ray photoelectron spectroscopy (ARXPS), which is one of the best methods to determine the thickness of the SAMs, ${ }^{40)}$ showed that the thiol, the ferrocene, and the porphyrin groups were aligned in this order and the total thick. ness and the distance between the $\mathrm{Fe}$ and outer most part of the SAM of the $\mathrm{PC}_{8} \mathrm{FcC}_{11} \mathrm{SH}$ molecule were $44 \AA$ and $29 \AA$, respectively. Thus, the alkyl chain connecting the porphyrin and ferrocene groups and that between the ferrocene group and the gold electrode were extended and the distance between the porphyrin moiety and the gold electrode was quite large. This is very suitable for the inhibition of electron transfer and energy transfer from the excited state of the porphyrin moiety to the gold electrode. The monolayer should also act as an effective barrier for the oxidation of $\mathrm{MV}^{+}$. The quantum efficiency increased with the increase of the number of methylene groups between ferrocene and porphyrin up to $11 .^{41)}$

\section{Concluding Remarks}

The formation process and electrochemical characteristics of the SAMs of thiol derivatives were clarified by various techniques. Several new optical properties were introduced onto the electrode surface by the SAMs of novel molecules. For the further development of the SAMs, several aspects should be mentioned. The formation of defectless SAMs is essential for the SAMs to be used in practical applications. In this respect, we have shown that the order of the SAMs is dependent on the solvent in which the SAM is formed. ${ }^{42)}$ The combination of the semiconductor properties is also very important. We have employed two methods. One method is to attach semiconductor nano-particles. We have demonstrated that well-ordered mono- and multi-layered structures of CdS and ZnS nano-particles can be formed via the SAMs of dithiols on gold. ${ }^{43-45)}$ The second method is to form the SAMs on semiconductor substrates. Several groups reported SAM formation on $\mathrm{Si}$ and we have used GaAs as the substrate. ${ }^{46)}$ The formation of the SAM with a two-dimensional chirality (Fig. 2h) may lead to a new chemistry. ${ }^{47)}$

\section{Acknowledgment}

The study on the self-assembled monolayer in our group was initiated when Dr. Yukari Sato joined the group in 1989 as a graduate student. The work has been extended by Drs. Toshihiro Kondo and Shen Ye, Prof. Bunsho Ohtani, many students of the group and several colleagues outside the group whose names are mentioned in the references. This work was supported by Grants-in-Aids for Scientific Research on Priority Areas of "New Functionality Materials", "Molecular Suprastructure", "New Development of Organic Electrochemistry", and "Electrochemistry of Ordered
Interfaces" from the Ministry of Education, Science, Sports, and Culture, Japan.

\section{References}

1) R. G. Nuzzo and D. L. Allara, J. Am. Chem. Soc., 105, 4481 (1983). One should, however, note that Taniguchi et al. (I. Taniguchi, K. Toyosawa, H. Yamaguchi, and K. Yasukouchi, J. Chem. Soc., Chem. Comm., 1032 (1982)) reported that 2,2'- bipyridyl disulfide irreversibly adsorbs on gold before the paper by Nuzzo and Allara.

2) A. Ulman, An Introduction to Ultrathin Organic Films from Langmuir-Blodgett to Self-Assembly, Academic Press, New York N.Y. (1991).

3) H. O. Finklea, Electroanalytical Chemistry, (Eds. A. J. Bard and I. Rubinstein); Vol. 19, p. 109, Marcel Dekker, New York N.Y. (1996).

4) A. Ulman, Chem. Rev., 96, 1533 (1996).

5) K. Shimazu, I. Yagi, Y. Sato, and K. Uosaki, Langmuir, 8, 1385 (1992).

6) Y. Sato, B. L. Frey, R. M. Corn, and K. Uosaki, Bull. Chem. Soc. Jpn., 67, 21 (1994).

7) D. D. Popenoe, R. S. Deinhammer, and M. D. Porter, Langmuir, 8, 2521 (1992).

8) M. D. Porter, T. B. Bright, D. L. Allara, and C. E. D. Chidsey, J. Am. Chem. Soc. 109, 3559 (1989).

9) R. Yamada and K. Uosaki, Langmuir, 13, 5218 (1997).

10) R. Yamada and K. Uosaki, Langmuir, 14, 855 (1998).

11) G. E. Poirier and E. D. Pylant, Science, 272, 1145 (1996).

12) C. Schonenberger, J. A. M. Sondag-Huethorst, J. Jorritsma, and L. G. J. Fokkink, Langmuir, 10, 611 (1995).

13) G. E. Poirier, Chem. Rev., 97, 1117 (1997).

14) C. A. Widrig, C. Chung, and M. D. Porter, J. Electroanal. Chem., 310, 335 (1991).

15) S. Ye, T. Haba, Y. Sato, K. Shimazu, and K. Uosaki, PCCP, 1, 3653 (1999).

16) K. Uosaki, Y. Sato, and H. Kita, Langmuir, 7, 1170 (1991).

17) T. Matsue, M. Suda, and I. Uchida, J. Electroanal. Chem., 234, 163 (1987).

18) K. Shimazu, I. Yagi, Y. Sato, and K. Uosaki, J. Electroanal. Chem., 372, 117 (1994).

19) Y. Sato, Ph. D. Thesis, Graduate School of Science, Hokkaido University (1994).

20) R. F. Cookson, Chem. Rev., 74, 5 (1974).

21) H. C. De Long, J. J. Donohue, and D. A. Buttry, Langmuir, 7, 1991 (1991).

22) G. K. Rowe and S. E. Creager, Langmuir, 7, 2307 (1991).

23) S. Ye, Y. Sato, and K. Uosaki, Langmuir, 13, 3157 (1997).

24) K. Shimazu, S. Ye, Y. Sato, and K. Uosaki, J. Electroanal. Chem., 375, 409 (1994).

25) T. Ohtsuka, Y. Sato, and K. Uosaki, Langmuir, 10, 3658 (1994).

26) T. Kondo, M. Takechi, Y. Sato, and K. Uosaki, J. Electroanal. Chem., 1995, 381, 203.

27) K. Shimazu, Y. Sato, I. Yagi, and K. Uosaki, Bull. Chem. Soc. Jpn., 67, 863 (1994).

28) Y. Sato and K. Uosaki, Denki Kagaku (presently Electrochemistry), 62, 1269 (1994).

29) Y. Sato, M. Fujita, F. Mizutani, and K. Uosaki, J. 
Electroanal. Chem., 409, 145 (1996).

30) S. Ye, A. Yashiro, Y. Sato, and K. Uosaki, J. Chem. Soc., Faraday Trans., 92, 3813 (1996).

31) K. Uosaki, Y. Sato, and H. Kita, Electrochim. Acta, 36, 1799 (1991).

32) Y. Sato, H. Itoigawa, and K. Uosaki, Bull. Chem. Soc. Jpn., 66, 1032 (1993).

33) Y. Sato and K. Uosaki, Denki Kagaku (presently Electrochemistry), 61, 817 (1993).

34) Y. Sato and K. Uosaki, J. Electroanal. Chem., 384, 57 (1995).

35) I. Yagi, S. Nakabayashi, and K. Uosaki, Surf. Sci., 406, 1 (1998).

36) T. Kondo, S. Horiuchi, I. Yagi, S. Ye, and K. Uosaki, J. Am. Chem. Soc., 121, 7155 (1999).

37) T. Kondo, T. Ito, S. Nomura, and K. Uosaki, Thin Solid Films, 284, 652 (1996).

38) T. Kondo, M. Yanagida, T. Ito, S. Nomura, and K. Uosaki, J. Electroanal. Chem., 438, 121 (1997).

39) K. Uosaki, T. Kondo, X.-Q. Zhang, and M. Yanagida, J. Am. Chem. Soc., 119, 8367 (1997).

40) Two methods are generally used to determine the thickness of the SAMs. One is ellipsometry and the other is ARXPS. One needs to know the refractive index and photoelectron mean free path of the SAM for ellipsometry and ARXPS, respectively, and usually it is assumed that they are same as those of the bulk crystals. This assumption is not necessarily valid, particularly when the coverage is low. We have recently proposed a novel method for the simultaneous determination of the thickness, $d$, and the photoelectron mean free path, $\lambda$, of SAMs by ARXPS and this method was applied for the $\mathrm{C}_{12} \mathrm{SH}$ SAM on $\mathrm{Au}(111)$ to demonstrate its usefulness ( $\mathrm{T}$. Kondo, M. Yanagida, K. Shimazu, and K. Uosaki, Langmuir, 14, 5656 (1998)).

41) T. Kondo, T. Kanai, K. Iso-o, and K. Uosaki, Z. Phys. Chem., 212, 23 (1999).

42) R. Yamada, Sakai, and K. Uosaki, Chem. Lett., 667 (1999).

43) T. Nakanishi, B. Ohtani, and K. Uosaki, Jpn. J. Appl. Phys., 36, 4053 (1997).

44) T. Nakanishi, B. Ohtani, K. Shimazu, and K. Uosaki, Chem. Phys. Lett., 278, 233 (1997).

45) T. Nakanishi, B. Ohtani, and K. Uosaki, J. Phys. Chem. B, 102, 1571(1998).

46) T. Baum, S. Ye, and K. Uosaki, Langmuir, in press (1999).

47) B. Ohtani, A. Shintani, and K. Uosaki, J. Am. Chem. Soc., 121, 6515 (1999). 